\title{
Prepare for Launch
}




\section{Erik Seedhouse}

\section{Prepare for Launch}

The Astronaut Training Process 
Dr Erik Seedhouse, F.B.I.S., As.M.A.

Milton

Ontario

Canada

SPRINGER-PRAXIS BOOKS IN SPACE EXPLORATION

SUBJECT ADVISORY EDITOR: John Mason, M.B.E., B.Sc., M.Sc., Ph.D.

ISBN 978-1-4419-1349-4 Springer Berlin Heidelberg New York

Springer is a part of Springer Science + Business Media (springer.com)

Library of Congress Control Number: 2009936077

Apart from any fair dealing for the purposes of research or private study, or criticism or review, as permitted under the Copyright, Designs and Patents Act 1988, this publication may only be reproduced, stored or transmitted, in any form or by any means, with the prior permission in writing of the publishers, or in the case of reprographic reproduction in accordance with the terms of licences issued by the Copyright Licensing Agency. Enquiries concerning reproduction outside those terms should be sent to the publishers.

(C) Copyright, 2010 Praxis Publishing Ltd., Chichester, UK

The use of general descriptive names, registered names, trademarks, etc. in this publication does not imply, even in the absence of a specific statement, that such names are exempt from the relevant protective laws and regulations and therefore free for general use.

Cover design: Jim Wilkie

Project copy editor: Christine Cressy

Typesetting: BookEns, Royston, Herts., UK 


\section{Contents}

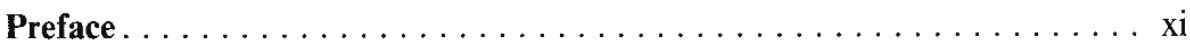

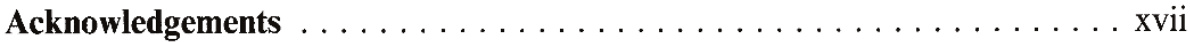

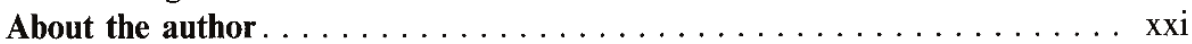

List of figures $\ldots \ldots \ldots \ldots \ldots \ldots \ldots \ldots \ldots \ldots \ldots \ldots \ldots \ldots \ldots \ldots \ldots \ldots$

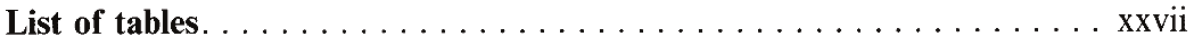

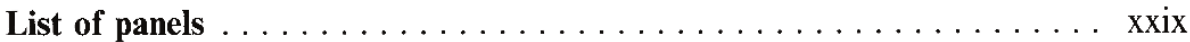

List of abbreviations and acronyms $\ldots \ldots \ldots \ldots \ldots \ldots \ldots \ldots \ldots \ldots \ldots \ldots$

Section I Astronaut Selection $\ldots \ldots \ldots \ldots \ldots \ldots \ldots \ldots \ldots \ldots \ldots$

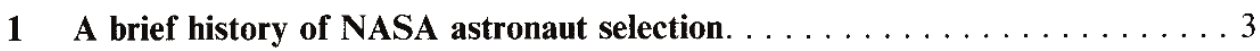

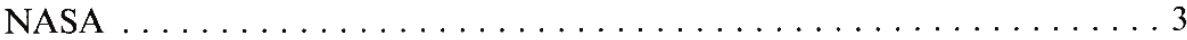

Selecting the Mercury astronauts ................. 4

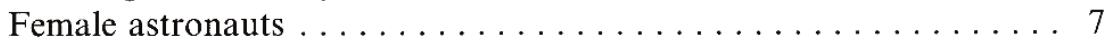

From Gemini to Shuttle........................ 8

Canadian Space Agency . . . . . . . . . . . . . . . . 12

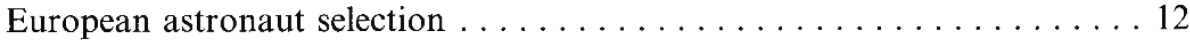

Reference............................ 13

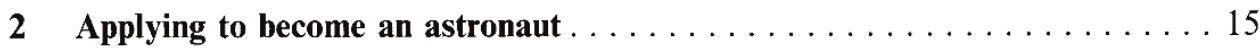

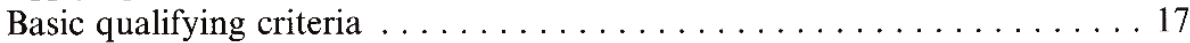

Education .............................. 17

Health and fitness .......................... 17

Miscellaneous experience . . . . . . . . . . . . . . . . . . 19

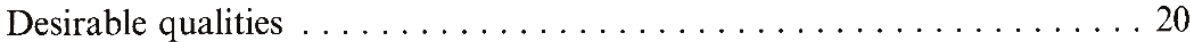

Patience . . . . . . . . . . . . . . . . . . . . . . . 20 20

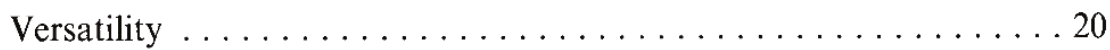

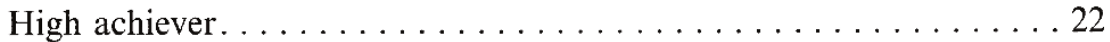

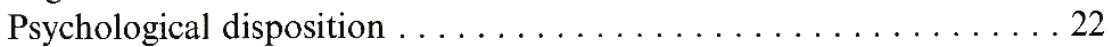

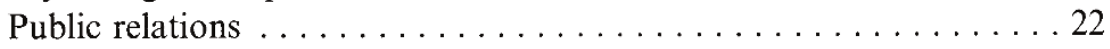




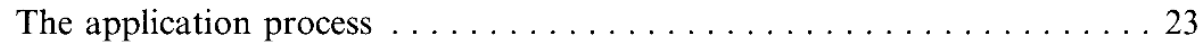

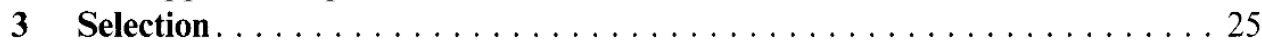

The trials and tribulations of being selected for the best job on and

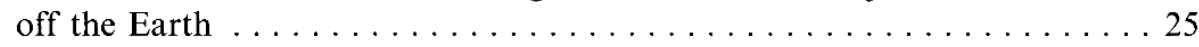

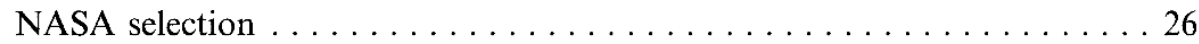

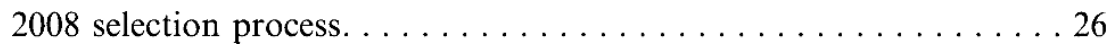

ESA astronaut recruitment campaign . . . . . . . . . . . . . . . . . 29

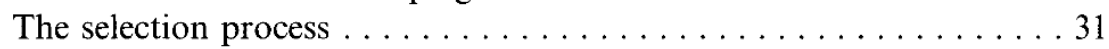

Canadian Space Agency . . . . . . . . . . . . . . . . . . . . . 34

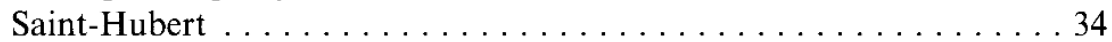

Halifax. . . . . . . . . . . . . . . . . . . . . . 39

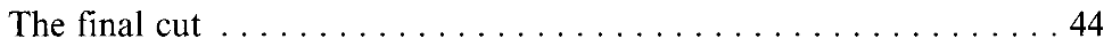

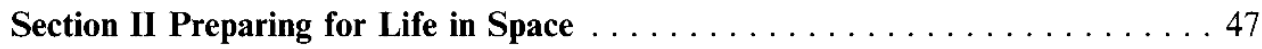

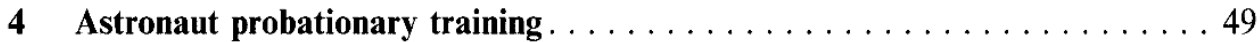

International Space Station training flow . . . . . . . . . . . . 49

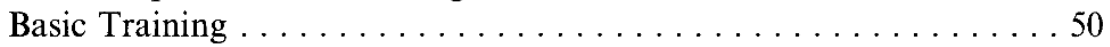

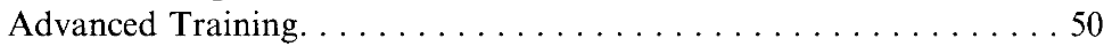

Increment-Specific Training . . . . . . . . . . . . . . . . . 50

European Space Agency . . . . . . . . . . . . . . . . . . . . 51

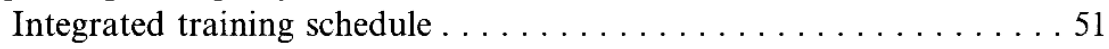

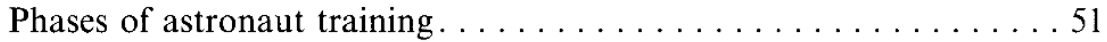

Advanced training . . . . . . . . . . . . . . . . . . . . 54

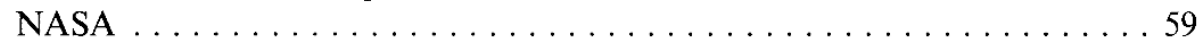

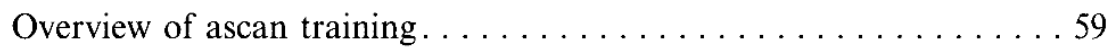

Ascan training week by week . . . . . . . . . . . . . . . . 60

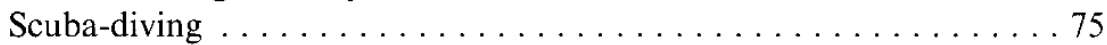

5 Technical assignments . . . . . . . . . . . . . . . . . 79

Types of technical assignments . . . . . . . . . . . . . . 79

Space Operations Mission Directorate . . . . . . . . . . . . 79

International Space Station Payloads Office. . . . . . . . . . 80

Extravehicular Activity Project Office . . . . . . . . . . . . 84

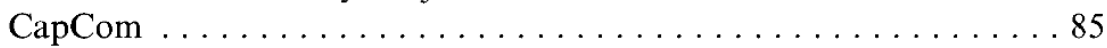

Flight Crew Operations Directorate . . . . . . . . . . . . . . . 86

Office of the International Space Station Program Scientist . . . . . . 86

Exploration Development Laboratory . . . . . . . . . . . . . 88

Russian Liaison . . . . . . . . . . . . . . . . . . . . . . . . . . . 88

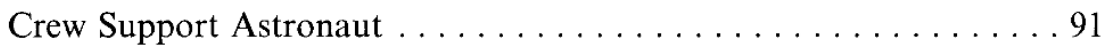

Public speaking ...................... 91

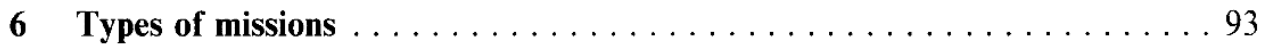

International Space Station missions. . . . . . . . . . . 93 
Expedition 17: July 23rd to end of November, $2008 \ldots \ldots \ldots 94$

Lunar missions . . . . . . . . . . . . . . . . . . . . . . . . . . . . 104

Surface activities . . . . . . . . . . . . . . . . . 104

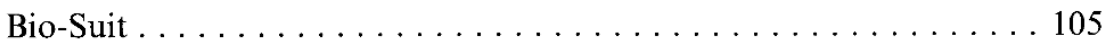

Science on the Moon . . . . . . . . . . . . . . . . . 107

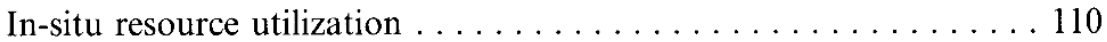

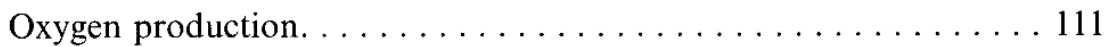

Mars mission . . . . . . . . . . . . . . . . . . . . 112

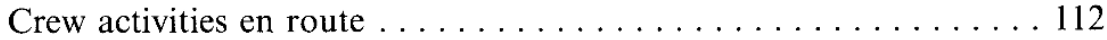

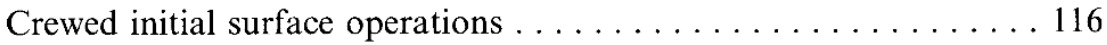

Crewed long-term surface operations . . . . . . . . . . . . 116

Departure preparations and departure . . . . . . . . . . . . 117

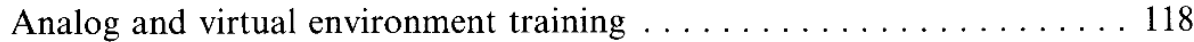

Virtual Environment Generator training. . . . . . . . . . 118

Analogs . . . . . . . . . . . . . . . . . . . 120

NASA Extreme Environments Mission Operations Project. . . . . . 122

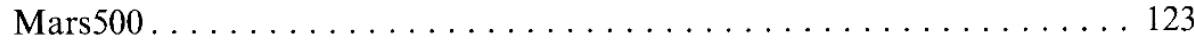

References ............................... 125

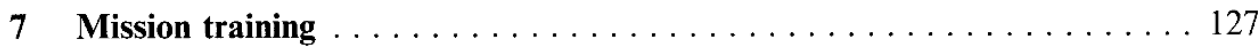

Increment-specific training . . . . . . . . . . . . . . . . . . . . 129

Crew qualification levels. . . . . . . . . . . . . . . . . . . . . 129

Emergency training and supplementary training . . . . . . . 130

European Space Agency training . . . . . . . . . . . . . . 131

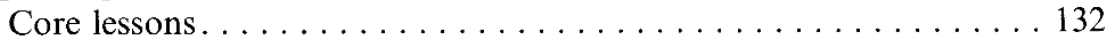

Rendezvous and docking . . . . . . . . . . . . . . . . . . 133

Attached phase operations . . . . . . . . . . . . . . . . 134

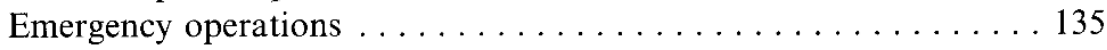

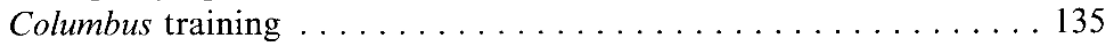

Expedition training. . . . . . . . . . . . . . . . . . 137

Team assignment . . . . . . . . . . . . . . . . 138

Training flow for a generic ISS mission $\ldots \ldots \ldots \ldots \ldots \ldots \ldots \ldots \ldots$

Russia Part I . . . . . . . . . . . . . . . . . . . . . . . 138

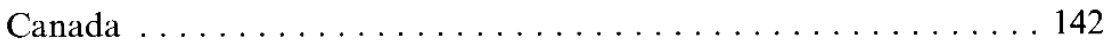

Russia Part II . . . . . . . . . . . . . . . . . . . . . . . . 147

United States Part I . . . . . . . . . . . . . . . . . . . . . . . . . . . . . . . . . . . . . . . . . . . . . . .

Russia Part III . . . . . . . . . . . . . . . . . . . . . . . 155

United States Part II . . . . . . . . . . . . . . . . . . . 163

References ........................... 172

8 Astronaut selection and training in the future $\ldots \ldots \ldots \ldots \ldots$

Future crew selection criteria . . . . . . . . . . . . . . . 173

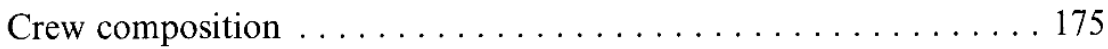

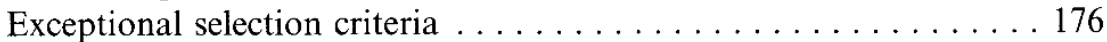

Genetic screening . . . . . . . . . . . . . . . . 177 
Precautionary surgery. . . . . . . . . . . . . . . . . . . . 179

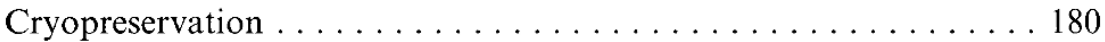

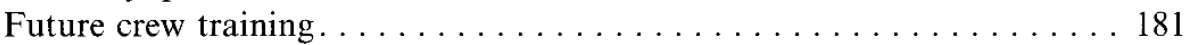

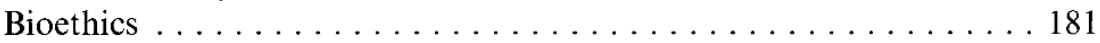

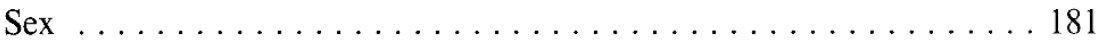

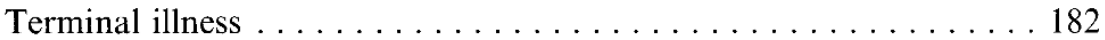

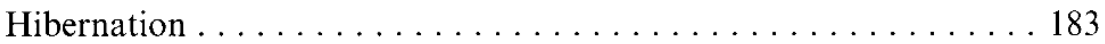

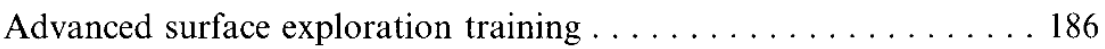

Bioinspired engineering of exploration systems . . . . . . . . 187

Artificial gravity indoctrination . . . . . . . . . . . . . . . . . 194

References .............................. 196

Section III Preparing for Launch . . . . . . . . . . . . . . . . . . . . . . . . 197

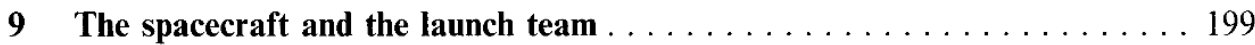

Launch vehicles . . . . . . . . . . . . . . . . . . . . . . . . . . . . 199

Ares I . . . . . . . . . . . . . . . . . . . . . 199

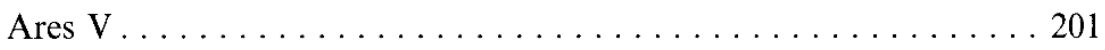

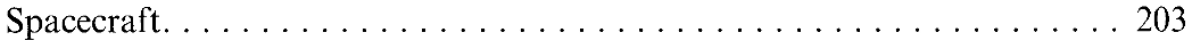

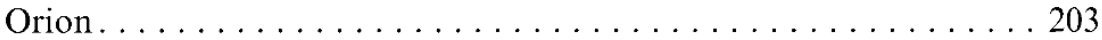

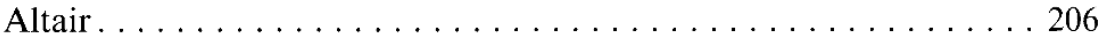

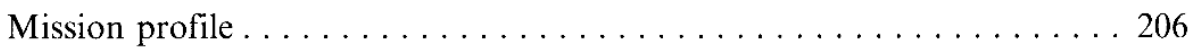

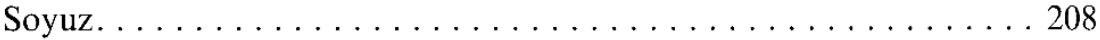

Launch teams............................. 209

Launch Director ....................... 211

Mission Control. . . . . . . . . . . . . . . . . . . 212

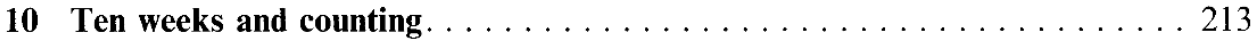

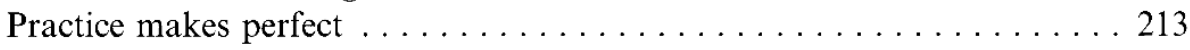

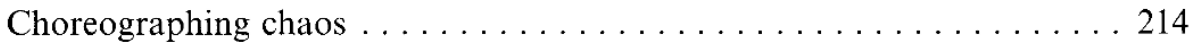

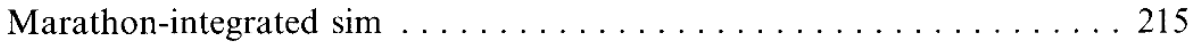

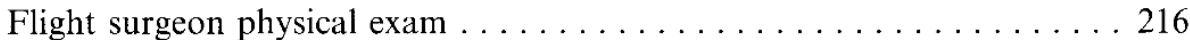

Packing for space . . . . . . . . . . . . . . . . . . 217

Terminal Countdown Demonstration Test . . . . . . . . . . . . . 219

Driving the M-113 escape tank ... . . . . . . . . . . . 219

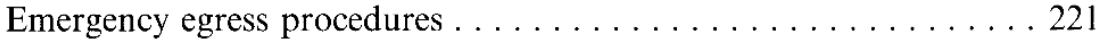

Terminal countdown demonstration test. . . . . . . . . . 222

Quarantine............................. 223

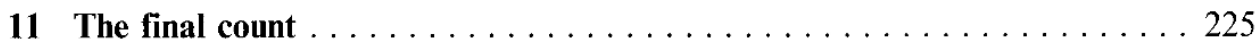

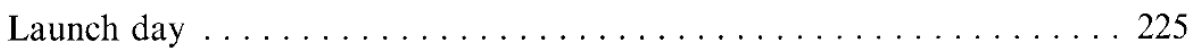

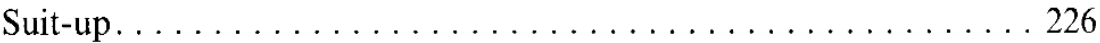

Inside the Astrovan . . . . . . . . . . . . . . . . . . . . . . . 229

White room ........................ 232 
Contents ix

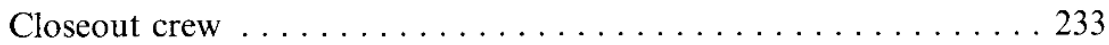

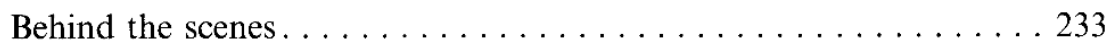

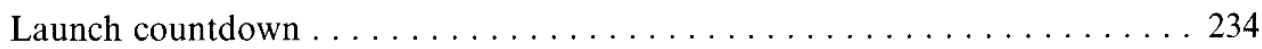

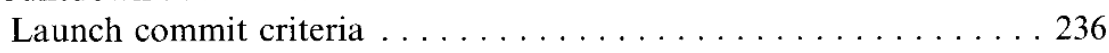

Communication ........................ 237

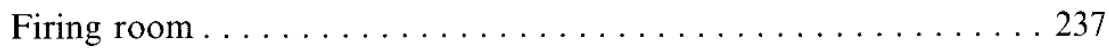

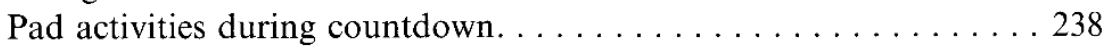

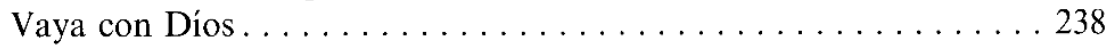




\section{Preface}

"I have always wanted to be an astronaut. Every kid growing up during the space race wanted to be an astronaut. Unlike most kids, however, I never vacillated in my career choices. I have a vivid memory of sitting on the lounge floor, watching the first lunar landing on my parents' black and white television set. Watching the images of the Saturn $V$ on the launch pad and astronauts bounding across the lunar surface, I resolved to become an astronaut. Only 5 years old at the time, the initial appeal for me of becoming an astronaut was riding a rocket and walking on the Moon.

As I learned more about what was required to be selected as an astronaut, I focused increasingly on achieving my dream. In 1987, knowing many astronauts had a military background, I joined the 2nd Battalion of the Parachute Regiment. Fortythree recruits started the 27 -week basic training to become a 'Para'. Just three of us were successful. I was one of the three.

During my time in the Paras, I was trained by the Special Air Service (SAS) in jungle and desert warfare, made night jumps from Chinook helicopters, and jumped out of a Hercules C-130 more times than I can remember. I also endured annual 80 $\mathrm{km}$ marches with a $20-\mathrm{kg}$ pack on my back and acquired advanced survival techniques in the jungles of Belize and the desert of northern Cyprus. During operational deployments, I gained extensive experience operating in the cohesive environment of a small team, while under considerable and prolonged stress. I enjoyed the training immensely, especially knowing it provided excellent experience for becoming an astronaut.

My first postgraduate degree was a Master's in Medical Science at Sheffield University. Rather than choose one of the research options offered by the course, I decided to pay Dr. David Grundy a visit. David was Director of the Institute for Space Biomedicine. Together, we formulated a space life-sciences research proposal focusing on head-down-tilt, the outcome of which was an article published in the Physiologist in 1991. While at Sheffield, I began to focus more on sports, with the goal of becoming a professional athlete.

On completing my Master's degree, I moved on to work in a Pulmonary Function 
Laboratory and learned how to balance budgets and develop test protocols. Shortly after starting work at the laboratory in March, 1992, I applied to the Canadian Astronaut Program. Since I had not yet accumulated the myriad qualifications required for a competitive application, my objective was to indicate to the CSA my interest in becoming an astronaut, with the intention of being able to submit a more competitive application when the next selection was advertised.

Although I realized the next selection might be many years away, my focus never wavered. My next goal was to experience microgravity and, to that end, I volunteered to be a subject in a study conducted by a colleague of Dr. Grundy. In April, 1995, I participated as a subject in the European Space Agency's 22nd Parabolic Flight Campaign, which provided me with valuable experience in performing equipment set-up, calibration, and monitoring in support of physiological testing. The data collection for the study took place over a 5-day period, flying 30 parabolas daily over the Bay of Biscay, providing me with ample opportunity to experience microgravity.

My increasing involvement in competitive sports culminated in my achieving a key ambition: that of becoming a professional athlete. This goal was accomplished after winning the World Endurance Triathlon Championships in 1995. During my triathlon career, I repeatedly demonstrated my commitment to my corporate sponsors, an enduring resolve, and the mental and physical fortitude enabling me to win what many considered impossible races. Winning world championship races was achieved by adhering to a strict and rigorous training regime and with the motivation to achieve distinction, a trait I consider an asset to any aspiring astronaut. Furthermore, due to my success, I was in regular demand by the media for interviews and gained invaluable experience as a representative for my corporate sponsors.

Shortly after becoming a professional triathlete, I moved to Germany, courtesy of a $\$ 50,000$ ESA grant. While studying for my Ph.D. at the Institute for Space Medicine, I had the opportunity to acquire a working knowledge of ESA's program of operation. My work at the Institute also provided me with experience related to a variety of space program development practices and extended my ability to interact with external and international scientific counterparts. I pursued my Ph.D. studies simultaneously with my sports career - a combination requiring me to work 70 or more hours a week. Apart from being an ideal place to conduct research, the Institute also provided an outstanding opportunity to accumulate expertise in space program procedures and acquire a working knowledge of space medicine.

Upon retiring as a triathlete in 1999, I pursued my post-doctoral qualification at Simon Fraser University's (SFU) Environmental Physiology Unit (EPU). While there, I envisioned the Extreme Physiology Program (EPP) and initiated field research trips to Mount McKinley and Aconcagua. The EPP was envisaged as a multi-science/technology research and development program in which studies of human physiology in stressful environments would be conducted. These studies included lab experiments (simulated space, high altitude, and deep sea) and field studies (using wireless technologies), the first of which was a simulated 5-day stay onboard the International Space Station. Later (field) studies included ascents of Mt. 
McKinley and Aconcagua to investigate the differences in physiological responses between athletes and non-athletes. As a Co-Director of the EPP, I directed, implemented, managed, and monitored research programs, and developed the priorities and objectives for research projects within the program.

In 2005, I was recruited by Bigelow Aerospace, Las Vegas, as an Astronaut Training Consultant. During my time at Bigelow Aerospace, I designed, wrote, and edited the Spaceflight Participants Training Manual, designed medical algorithms for spaceflight medical emergencies, and developed instructional materials. I also designed, wrote, and edited the Chief Medical Officer's Manual for spaceflight participant selection and designed and edited astronaut certification standards for spaceflight participants.

In 2007, I joined the Aerospace Group at the Defence and Research Development Canada (DRDC) in Toronto, to work as a program manager overseeing specialized research development projects.

Curiosity has always gotten the better of me. I enjoy scuba-diving, climbing mountains, writing books, racing Ironman triathlons, flying my Cessna, and writing and directing movies. My quirk is that I prefer technical manuals to television and I hate sitting still. I cannot resist new activities and enjoy squeezing as many projects into my life as possible. I consider the ability to display competence, self-reliance, and the ability to work effectively even under the most challenging conditions as traits required by an astronaut and I believe I possess those qualities. Having varied experiences and adapting well to their demands is a desirable characteristic for an astronaut and I consider my background supports this requirement.

My varied work experience has provided me with the opportunity to develop excellent communication skills, both written and verbal. I have contributed extensively to Spaceflight magazine, been interviewed on numerous occasions, published four books, and have worked as a motivational speaker. As an expedition leader, I utilized logistical skills to achieve successful outcomes in dynamic and challenging environments. I consider these and the other aforementioned skills to be key to my effective contribution to the CSA and I am confident in my ability to respond to the challenges of being a Canadian astronaut.

As a potential astronaut, I have demonstrated a willingness to accept physical hazards, a capacity to tolerate rigorous and severe environmental conditions, and the ability to react assertively under conditions of duress. These abilities have been demonstrated during parachute jumps, mountaineering, diving, triathlon, microgravity research, and as an instructor during high-altitude indoctrination training.

As an astronaut, I believe I will be an asset to the CSA. My varied scientific experience, combined with my athletic career and military training, have provided me with a unique background that has inculcated a calm, methodical, and cautioned approach to problem solving, whether in a laboratory or under conditions of prolonged physical and mental duress. I am easy to work with and integrate easily within a team and I believe I can provide the same support, encouragement, and honesty to fellow co-workers and astronauts.

Throughout my career, I have maintained an enduring, positive commitment to manned spaceflight, my life's one overriding passion. I have been reading about and 
studying spaceflight since that day I watched the Moon landings. I want to join the Canadian Astronaut Team because it is the best occupation to fully utilize my professional skills and experience, and because it is a profession in which I could contribute the most to the CSA in its execution of Canada's space policy. I would be privileged to join the Canadian Astronaut Team, who have raised teamwork to a new level, made excellence a given, and challenged conventional thinking with courage and imagination. I am ready and eager to be a part of that team."

One of the first stages of the CSA's 2008 Astronaut Recruitment Campaign required applicants to write an essay explaining why they wanted to be an astronaut. The essay you have just read was the one I submitted. After a year of selection tests, including sea survival, fighting fires, robotics assessment, and a myriad other trials and evaluations, I made it to the final 30. Unfortunately, I didn't make it any further. For those applicants who had dedicated 20 years or more to the goal of becoming an astronaut, the blow was devastating to put it mildly. Unlike NASA, which routinely recruits astronauts, the CSA's campaign was only the third since 1983. For many of those deselected at the final stage who had waited 16 years since the CSA's 1992 campaign, it was the end of the road. The lucky few who worked in the US indicated they would apply for a Green Card with the intent of applying to NASA at the next campaign. Others returned to their jobs in academia, flying jets, or performing research. A small number found themselves recalibrating their life, trying to find another challenge. For example, one of the most highly qualified candidates confided to me he really didn't like his job (he is one of the world's leading emergency physicians and an Everest summiteer) and was considering climbing K2. Some reflected on the high price they had paid in the personal lives (many had burned through more than one marriage) by following a dream demanding sacrifices few can fathom. Then there were candidates such as myself who set their sights on achieving their goal by gaining employment (and hopefully a flight!) with one of the fledgling private space companies such as Virgin Galactic and SpaceX.

The road to becoming an astronaut is one demanding tremendous sense of direction, perspective, resolve, and extraordinary self-confidence. While many have entertained thoughts of becoming an astronaut, few ever embark upon the journey requiring them to accumulate the myriad qualifications essential for a competitive application. Those ultimately selected are already some of the most highly trained humans on the planet, yet the preparation for their new occupation hasn't even begun! Here, in this book, you will learn how these extraordinarily qualified and uniquely gifted people learn to be astronauts and how their unique training prepares them to do the most exciting, rewarding, and fulfilling job on and off the Earth.

\section{Outline of the Chapters}

There have been several books written by astronauts describing the challenges of training and preparing for spaceflight, but most of these have focused on time in orbit. Thanks to first-person accounts such as Sky Walking by Tom Jones, and 
Riding Rockets by Mike Mullane, armchair spacefarers have the opportunity to gain an insight into the orbital adventures of astronauts. The objective of this book, however, is to describe the nuts and bolts of astronaut training, starting with the application process and finishing with the climactic ride into space.

Section I starts with the application and selection process. As a two-time applicant to become an astronaut with the Canadian Space Agency (CSA), the author reveals what it takes to assemble a competitive application and describes the stringent selection criteria used by space agencies to select future astronauts.

Section II begins with a generic chronology of an astronaut's probationary training at Johnson Space Center (JSC). From spending freezing nights in the Absaroka Mountains learning how to survive on rabbit stew, to pulling Gs in T-38s, the author describes the myriad training elements comprising an astronaut candidate's (ascan) first step towards becoming a fully fledged astronaut. Section II also provides an insight into the world of technical assignments, the seemingly never-ending wait for a flight, and an overview of the types of missions astronauts will be flying over the next two decades. Following a detailed account of the multitude of training elements comprising mission training, the author peers into the future by describing the advantages of hibernation and the challenges of bioethics training.

Before Section III delves into the high-intensity world of pre-launch preparation, the author provides an overview of NASA's new family of launch vehicles and spacecraft that will transport astronauts to the International Space Station (ISS), the Moon and, eventually, Mars. Following a "behind-the-scenes" glimpse of the launch team, the reader is guided through the final 10 weeks of mission training and preparation ultimately leading to launch day. 


\section{Acknowledgments}

In writing this book, I have been fortunate to have had my wife, Doina, as my proofreader. Once again, she has applied her considerable skills to make the text as smooth and coherent as possible. Any remaining shortcomings are my responsibility and mine alone.

I am also grateful to the five reviewers who made such positive comments concerning the content of this publication and to Clive Horwood and his team at Praxis for guiding this book through the publication process. The author also gratefully acknowledges Christine Cressy and BookEns, whose attention to detail and patience greatly facilitated the publication of this book. Thanks also to Jim Wilkie for creating the cover of this book.

Once again, no acknowledgment would be complete without special mention of our cats, Jasper and MiniMach, who provided endless welcome distraction and entertainment. 
This book is dedicated primarily to my wife, without whom I would never have had the opportunity to pursue my dream.

It is also dedicated to those who helped me along the way, such as Professor David Grundy, Professor Paul Enck, and Parvez Kumar.

Finally, this book is dedicated to Heike, Rolf, Christian, Mark, and dozens of other supremely qualified individuals who, due to myopic political agendas or by not having the right passport, were denied an opportunity to demonstrate their talents as astronauts. 


\section{About the author}

Erik Seedhouse is an aerospace scientist whose ambition has always been to work as an astronaut. After completing his first degree in Sports Science at Northumbria University, the author joined the legendary 2nd Battalion the Parachute Regiment, the world's most elite airborne regiment. During his time in the "Paras", Erik spent 6 months in Belize, where he was trained in the art of jungle warfare and conducted several border patrols along the Belize-Guatemala border. Later, he spent several months learning the intricacies of desert warfare on the Akamas Range in Cyprus. He made more than 30 jumps from a Hercules $\mathrm{C} 130$ aircraft, performed more than 200 abseils from a helicopter, and fired more light anti-tank weapons than he cares to remember!

Upon returning to the comparatively mundane world of academia, the author embarked upon a Master's degree in Medical Science at Sheffield University. He supported his Master's degree studies by winning prize money in $100 \mathrm{~km}$ ultradistance running races. Shortly after placing third in the World $100 \mathrm{~km}$ Championships in 1992 and setting the North American $100 \mathrm{~km}$ record, the author turned to ultradistance triathlon, winning the World Endurance Triathlon Championships in 1995 and 1996. For good measure, he also won the inaugural World Double Ironman Championships in 1995 and the infamous Decatriathlon, the world's longest triathlon, an event requiring competitors to swim $38 \mathrm{~km}$, cycle $1,800 \mathrm{~km}$, and run $422 \mathrm{~km}$. Non-stop!

Returning to academia once again in 1996, Erik pursued his Ph.D. at the German Space Agency's Institute for Space Medicine. While conducting his Ph.D. studies, he still found time to win Ultraman Hawaii and the European Ultraman Championships as well as completing the Race Across America bike race. Due to his success as the world's leading ultradistance triathlete, Erik was featured in dozens of magazines and television interviews. In 1997, GQ magazine nominated him as the "Fittest Man in the World"'.

In 1999, Erik decided it was time to get a real job. He retired from being a professional triathlete and started his post-doctoral studies at Vancouver's Simon Fraser University's School of Kinesiology. While living in Vancouver, Erik gained his pilot's license, started climbing mountains, and took up sky-diving to relax in his 


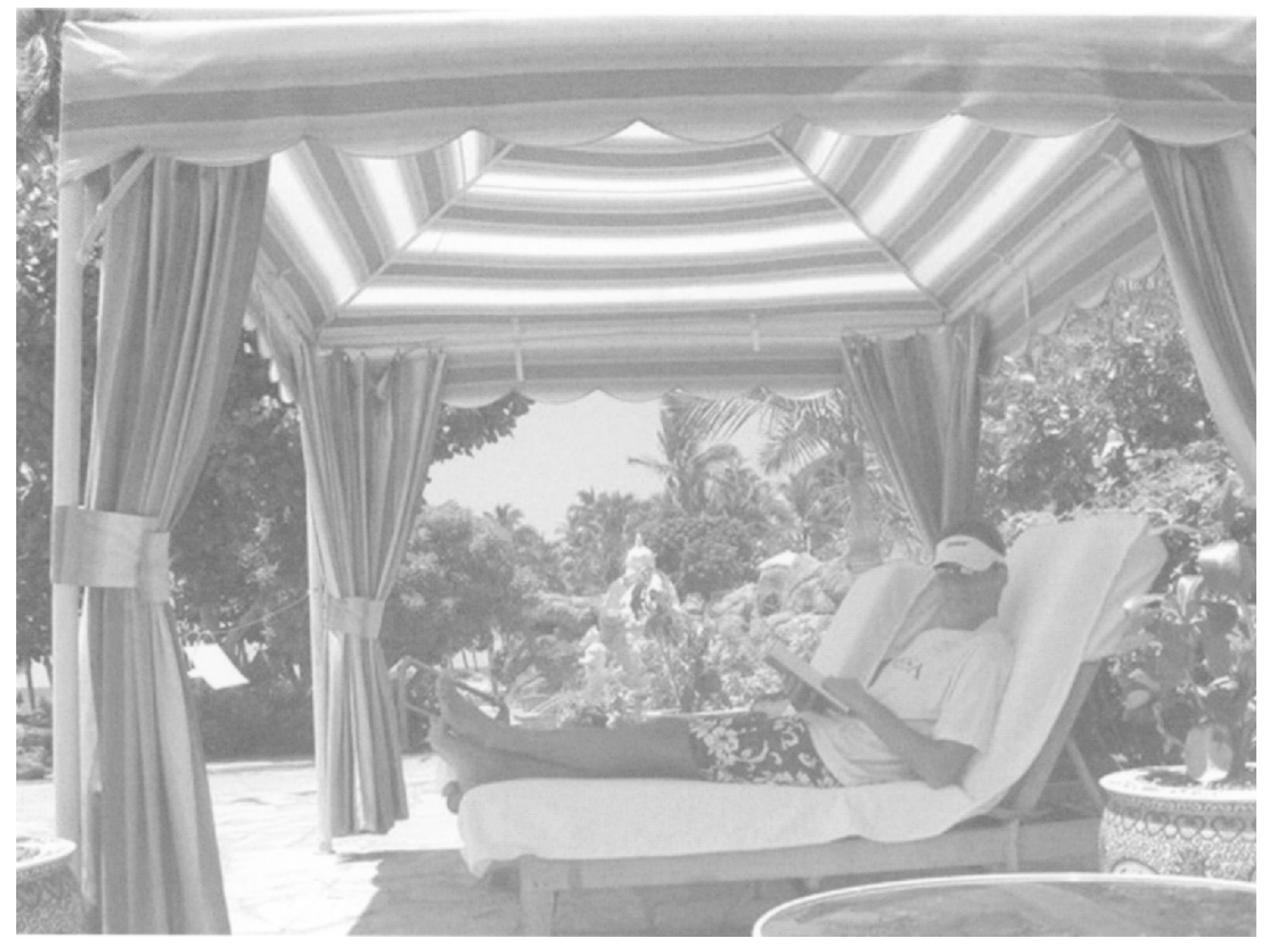

spare time. In 2005, the author worked as an astronaut training consultant for Bigelow Aerospace in Las Vegas and wrote Tourists in Space, a training manual for spaceflight participants. He is a Fellow of the British Interplanetary Society and a member of the Aerospace Medical Association. Recently, he was one of the final 30 candidates of the Canadian Space Agency's Astronaut Recruitment Campaign. Erik currently works as manned spaceflight consultant and author. He plans to travel into space with one of the private spaceflight companies. As well as being a triathlete, skydiver, pilot, and author, Erik is an avid scuba-diver and has logged more than 200 dives in more than 20 countries. His favorite movie is the director's cut of Blade Runner, his favorite science fiction authors are Allen Steele and Stanislav Lem, and his favorite science fiction series is Red Dwarf. Prepare for Launch is his fifth book. When not writing, he spends as much time as possible in Kona on the Big Island of Hawaii and at his real home in Sandefjord, Norway. Erik lives with his wife and two cats on the Niagara Escarpment in Canada. 


\section{Figures}

1.1 Ed White performs America's first spacewalk............ 4

$1.2 \quad$ Pete Conrad........................... 6

1.3 Bob Crippen examines a spacesuit designed for the Manned

Orbiting Laboratory program $\ldots \ldots \ldots \ldots \ldots \ldots \ldots \ldots$

1.4 The dawn of the Space Shuttle program.............. 11

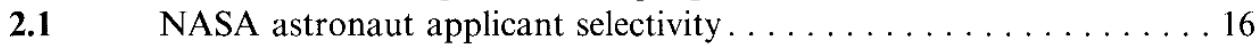

2.2 Canadian Space Agency astronaut, Bob Thirsk ............ 21

3.1 NASA's Class of 2009 Educator Astronauts. . . . . . . . . . . . . . 29

3.2 The ESA's Astronaut Class of $2009 \ldots \ldots \ldots \ldots \ldots \ldots \ldots$

3.3 Canadian Space Agency astronaut applicants performing the Multi-Stage Fitness Test. . . . . . . . . . . . . . . . . . 36

3.4 CSA astronaut applicants, Kenneth Welch and Bruce Woodley . . . . 37

3.5 CSA astronaut applicant, Chris Denny, "flies" the Canadarm2 . . . . 38

3.6 CSA astronaut applicants being assessed during a hazardous

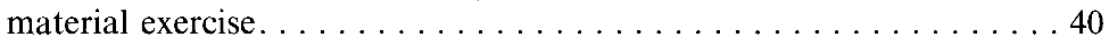

3.7 A CSA astronaut applicant, Chris Denny, constructs a strongback . . 41

3.8 CSA astronaut applicants patch a fire main during an assessed

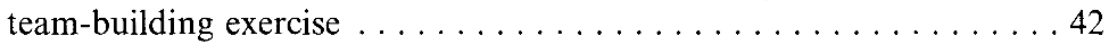

3.9 CSA astronaut applicants being evaluated inside Survival Systems' helo-dunker . . . . . . . . . . . . . . . . . . . 43

3.10 CSA astronaut applicant, Joshua Kortryk, sits during a 3D anthropometric assessment. . . . . . . . . . . . . . . . 44

3.11 David Saint-Jacques, Industry Minister Tony Clement, and Jeremy Hansen. . . . . . . . . . . . . . . . . . . . . . 45

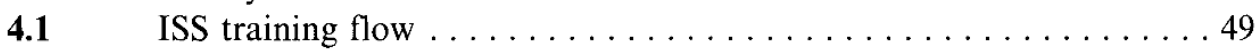

4.2 The ESA's Astronaut Training Center, in Cologne, Germany. . . . . . 52

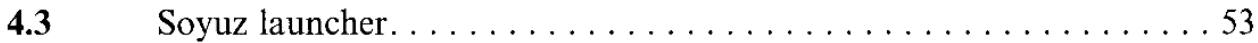

4.4 Jules Verne Automated Transfer Vehicle approaches the

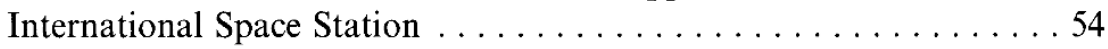

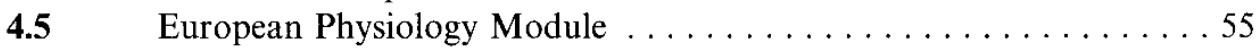


4.6 The ESA's EVA pre-familiarization training takes place at the EAC, in Cologne . . . . . . . . . . . . . . . . . . 57

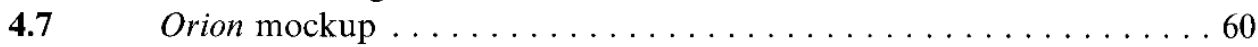

4.8 NASA Educator Mission Specialist, Joseph M. Acaba, gives an

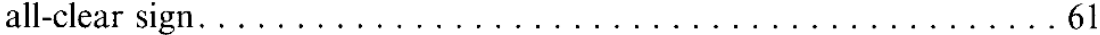

4.9 One of NASA's Class of 2004 prepares for his helo-dunker

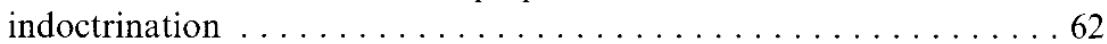

4.10 Duncan Milne tests the built-in breathing device with his daughter . 63

4.11 Simon Fraser University's hypobaric chamber . . . . . . . . . 63

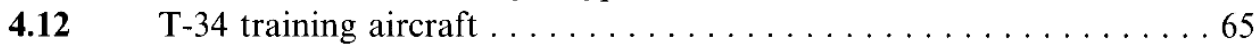

4.13 NASA's Class of 2004 ascans test their navigation skills in the wilderness of Maine . . . . . . . . . . . . . . 66

4.14 NASA Class of 2004 ascans "rescue" a classmate during survival

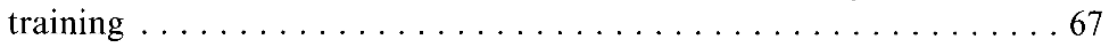

4.15 Two T-38s fly over Edwards Air Force Base . . . . . . . . . 68

4.16 Some of NASA's 2004 class of astronaut candidates and some JAXA astronauts tumble during one of a series of reduced gravity

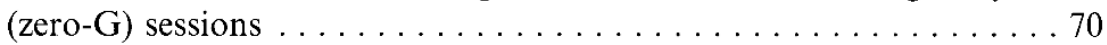

4.17 Artist's rendering of Ares $I$ on the launch pad . . . . . . . . 71

4.18 Astronauts sit in the suit prep room in the Advanced Crew Escape System suits . . . . . . . . . . . . . . . . . . . 74

4.19 The Maximum Absorbency Garment . . . . . . . . . . . . 74

4.20 NASA's astronaut candidates train in the Neutral Buoyancy Laboratory. . . . . . . . . . . . . . . . . . . . . . 76

4.21 Astronauts test an Orion mockup. . . . . . . . . . . . . 77

5.1 Space Operations Mission Directorate organizational structure . . . .80

5.2 Spacesuit engineer, Dustin Gohmert, simulates work in a mock crater in JSC's Lunar Yard . . . . . . . . . . . . . . . . . . . . . . . . . 84

5.3 NASA's Mission Control Center, with CapCom on the right . . . . . 86

5.4 Low-fidelity mockup of NASA's Orion crew exploration vehicle . . . 89

$5.5 \quad$ Panel display inside Orion mockup. . . . . . . . . . . . 90

6.1 Sergei Volkov, Oleg Kononenko, and Greg Chamitoff take a break

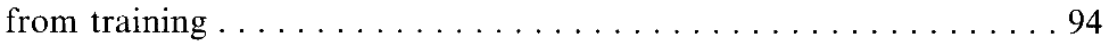

6.2 The International Space Station and the ESA's Automated Transfer Vehicle. . . . . . . . . . . . . . . . . . . . . . 97

6.3 Tropical Storm Edouard captured from the International Space

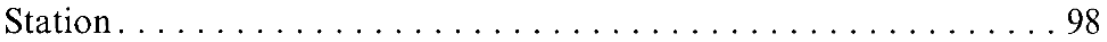

6.4 Greg Chamitoff considers his strategy carefully as he prepares for his next move. . . . . . . . . . . . . . . . . . 99

6.5 Flight Director, Chris Edelen, considers a move he hopes will stop Earth's losing streak. . . . . . . . . . . . . . . . . . . . . 99

6.6 Chamitoff works in the Kibo laboratory to move an experiment rack . . . . . . . . . . . . . . . . . . . . . . . . . 100

6.7 The ESA's ATV begins its relative separation from the International Space Station 
6.8 Astronauts conduct one of several extravehicular activities during Expedition $17 \ldots \ldots \ldots \ldots \ldots \ldots \ldots \ldots . \ldots \ldots \ldots$

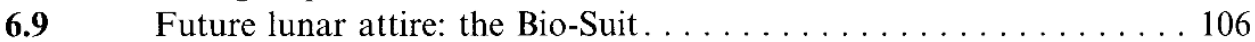

6.10 Artist's rendering of astronaut conducting seismic exploration on the Moon. . . . . . . . . . . . . . . . . . . . . . . . 108

6.11 One iteration of NASA's lunar rover . . . . . . . . . . . . 109

6.12 Artist's rendering of a Mars crew extracting core samples . . . . . 118

$6.13 \quad$ Virtual Environment Generator ........................ 119

6.14 Josef F. Schmid and Jose M. Hernandez participate in an underwater extravehicular activity session .............. 122

6.15 Overhead view of the isolation chamber used in the ESA's Mars500 mission ............................ 124

7.1 Current configuration of the International Space Station . . . . . . 129

7.2 Robert Thirsk participates in a training session in an ISS mockup . 130

7.3 The European Space Agency's Automated Transfer Vehicle...... 132

7.4 The European Space Agency's Columbus laboratory. . . . . . . . . . . 135

7.5 The Columbus laboratory mockup .................. 136

7.6 Canadian astronaut, Robert Thirsk, sits inside the cramped interior of the Soyuz. . . . . . . . . . . . . . . . . . . . 141

7.7 Canadian astronaut, Robert Thirsk, dons the Sokol spacesuit . . . . 143

7.8 Scott E. Parazynski works with cables linked to the Canadarm2 . . 144

7.9 Dextre is a sophisticated dual-armed robot, part of Canada's contribution to the ISS . . . . . . . . . . . . . . . . . . 145

7.10 Julie Payette practices using the Mobile Servicing System Operations Training Simulator.................... 146

7.11 Engineers pour plaster into the Soyuz seat liner to ensure a comfortable fit . . . . . . . . . . . . . . . . . . . . . . . 149

7.12 NASA's Neutral Buoyancy Laboratory . . . . . . . . . . . 150

7.13 Divers assist astronauts during their simulated EVAs.......... 151

7.14 The Absaroka Mountains . . . . . . . . . . . . . . . . 154

7.15 Robert Thirsk practices firing a weapon in preparation for his upcoming mission ........................ 156

7.16 NASA's Extravehicular Mobility Unit . . . . . . . . . . . 156

7.17 The Russian Orlan-M spacesuit . . . . . . . . . . . . . . 157

7.18 Canadian astronaut, Robert Thirsk, models the colorful Forel suit . 159

7.19 Star City's centrifuge . . . . . . . . . . . . . . . . . 162

7.20 Running on the International Space Station's treadmill ......... 166

7.21 Medical algorithm used by crews on the International Space Station. . . . . . . . . . . . . . . . . . . . . . . . 169

7.22 Testing different telemedicine architectures in the Gagarin Cosmonaut Training Center, Star City, Russia............. 171

8.1 Plans to land astronauts on Mars will require new selection and training procedures $\ldots \ldots \ldots \ldots \ldots \ldots \ldots \ldots \ldots \ldots \ldots \ldots \ldots \ldots$

8.2 Future crew selection policies may echo those portrayed in the film Gattaca . . . . . . . . . . . . . . . . . . . . . . . . . . . . . . . . 177 
8.3 Sir Ernest Shackleton. . . . . . . . . . . . . . . . . . . . 182

8.4 Astronauts hibernating on their way to Mars may sleep in hibernaculums . . . . . . . . . . . . . . . . . . . . . . 184

8.5 California Ground Squirrel (Spermophilus beecheyi) . . . . . . . 184

$8.6 \quad$ A future Mars base . . . . . . . . . . . . . . . . . . 187

8.7 An inflatable habitat that may be used to construct a Mars base . . 188

8.8 Haughton Crater on Devon Island, Canada . . . . . . . . . . . 190

8.9 The gecko may hold the key to spacesuits capable of scaling walls. . 193

$8.10 \quad$ NASA's short-radius centrifuge . . . . . . . . . . . . . . . . 194

8.11 Configuration of mannequin and centrifuge in Wyle's lab in Houston. . . . . . . . . . . . . . . . . . . . . . . . . . . . . . 195

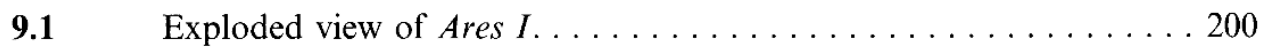

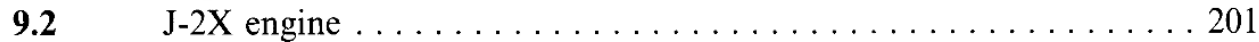

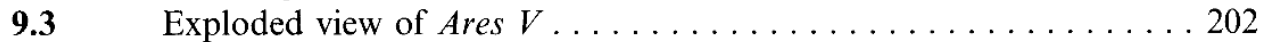

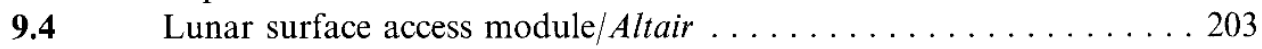

9.5 Orion . . . . . . . . . . . . . . . . . . . . . . . . 204

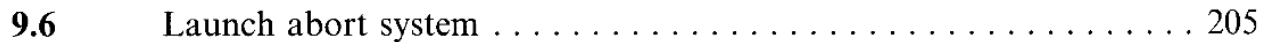

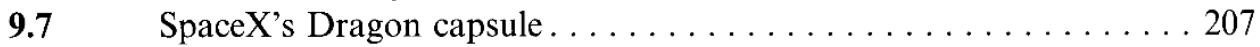

9.8 The Russian Soyuz capsule . . . . . . . . . . . . . . . 208

10.1 Astronauts put NASA's M-113 escape tank through its paces . . . . 220

10.2 NASA's new emergency escape system . . . . . . . . . . . 221

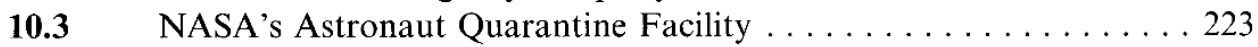

11.1 Kylie Clem and Gennady Padalka with astronauts, Michael Barratt and Tim Kopra ....................... 226

11.2 Astronauts suit up, assisted by a United Space Alliance suit technician. . . . . . . . . . . . . . . . . . . . 227

11.3 The crew exits the Operations and Checkout Building en route to

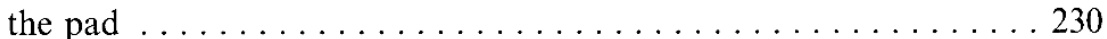

$11.4 \quad$ NASA's Astrovan . . . . . . . . . . . . . . . . . . . 231

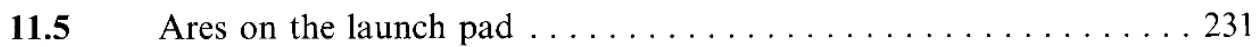

11.6 The "white room" .......................... 232

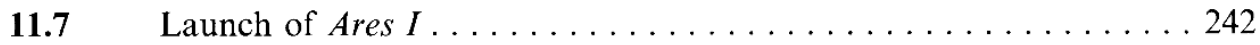

The colour section appears between pages 156 and 157. 


\section{Tables}

1.1 Hazards of manned spaceflight. .................. 3

2.1 Medical disqualification during 1992 CSA astronaut recruitment ... . 19

3.1 NASA astronaut selection schedule . . . . . . . . . . . . 27

3.2 NASA medical examinations and parameters ............. 27

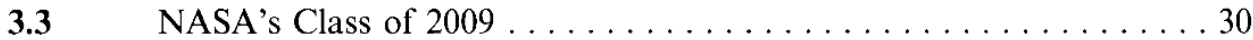

3.4 The ESA's astronaut selection schedule ................ 31

3.5 Total number of ESA applicants at the closure of the application

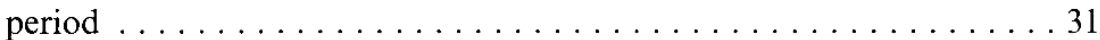

3.6 ESA medical examinations and parameters $\ldots \ldots \ldots \ldots \ldots \ldots 32$

3.7 The six candidates selected after formal panel interview . . . . . . . . 34

3.8 Canadian Space Agency astronaut selection schedule .......... 35

3.9 Breakdown of the top 40 astronaut candidates by region . . . . . . 35

3.10 The CSA's Class of $2009 \ldots \ldots \ldots \ldots \ldots \ldots \ldots \ldots \ldots \ldots \ldots$

4.1 The ESA's Neutral Buoyancy Facility characteristics . . . . . . . 58

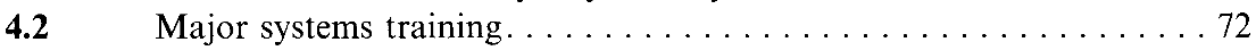

5.1 Examples of payload policies and requirements . . . . . . . 82

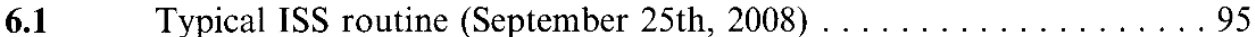

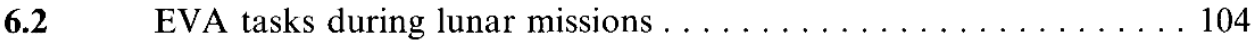

6.3 Scientific and human interest-driven activities . . . . . . . . . 117

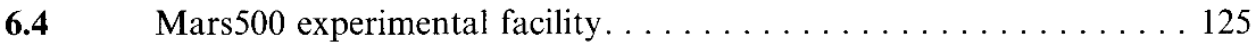

7.1 Mission training centers ......................... 127

7.2 The European Space Agency's ATV increment-specific training flow . . . . . . . . . . . . . . . . . . . . . 131

7.3 Daily dive operations in the Neutral Buoyancy Laboratory . . . . . 153

7.4 Categorization of light-loss criteria . . . . . . . . . . . . 161

7.5 Run schedule for determination of G-sensitivity. . . . . . . . 163

7.6 Classification of illnesses and injuries in spaceflight . . . . . . . 167

7.7 NASA medical training for International Space Station crewmembers . . . . . . . . . . . . . . . . . . . . . . 168

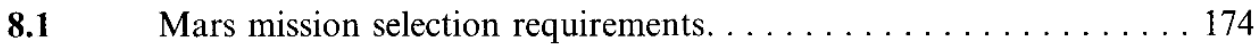

8.2 Bioethical selection and training issues for long-duration missions . 181 


\section{xxviii Tables}

8.3 Effect of hibernation on life support requirements . . . . . . . 183

$9.1 \quad$ Primary firing room positions $\ldots \ldots \ldots \ldots \ldots \ldots \ldots \ldots \ldots \ldots \ldots \ldots \ldots \ldots$

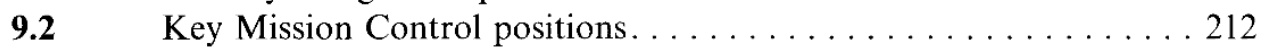

10.1 L-30 flight surgeon physical examination for long-duration crews . . 216

10.2 Robert Thirsk's music selection (ISS Expedition 20/21, 2009) . . . . 218

10.3 Robert Thirsk's official flight kit (ISS Expedition 20/21, 2009) . . . . 219

11.1 Launch countdown milestones . . . . . . . . . . . . . . 235 


\section{Panels}

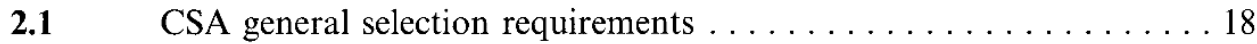

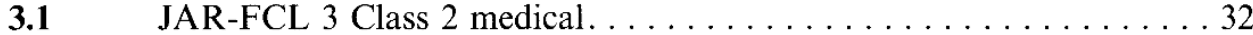

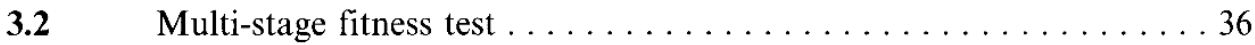

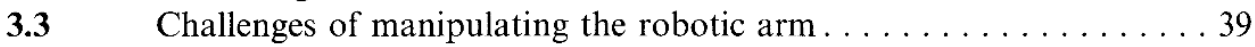

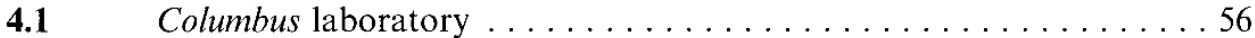

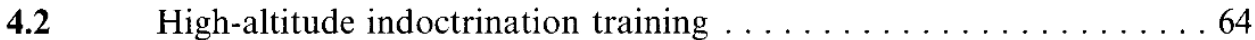

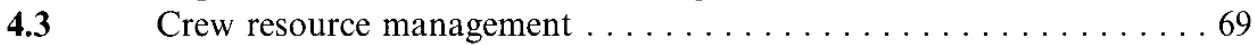

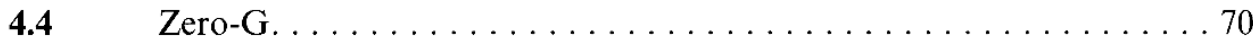

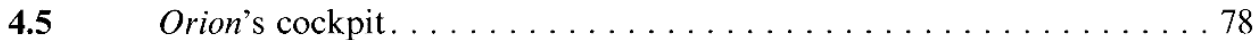

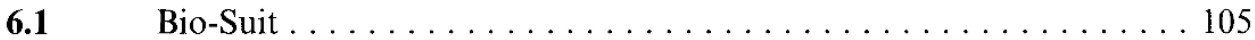

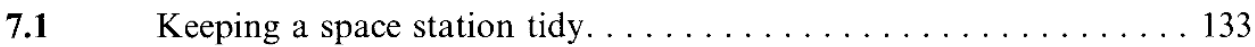

7.2 International Space Station Training Lead . . . . . . . . . . . 138

$7.3 \quad$ Speaking Russian . . . . . . . . . . . . . . . . . . . 140

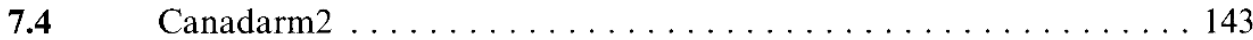

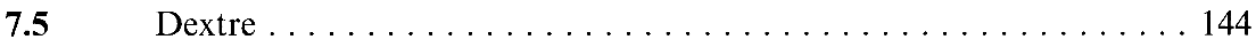

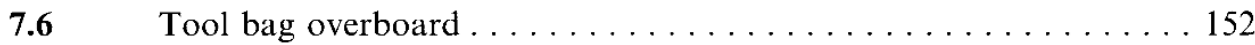

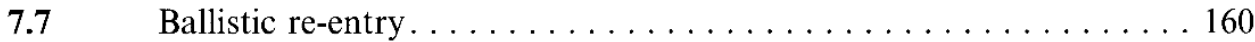

7.8 Science onboard the International Space Station . . . . . . . . . . 165

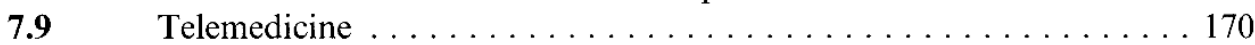

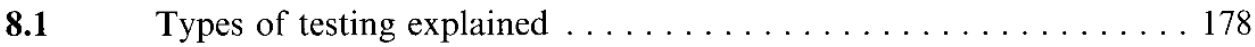

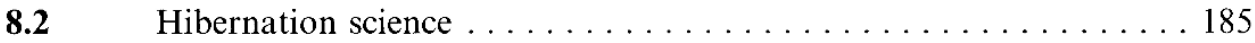

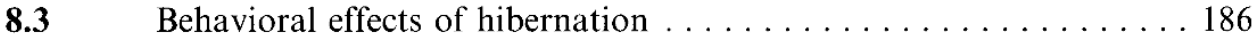

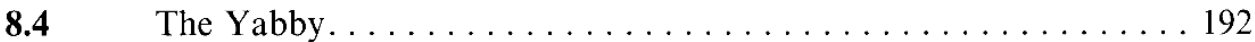

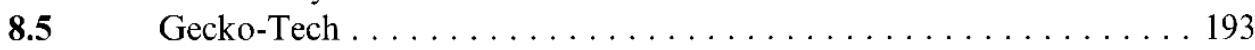

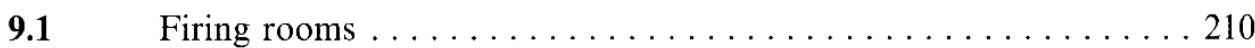

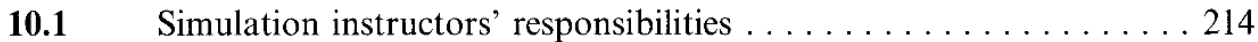

10.2 NASA's rollercoaster emergency escape system . . . . . . . . 222

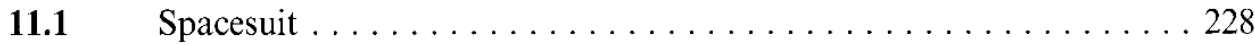

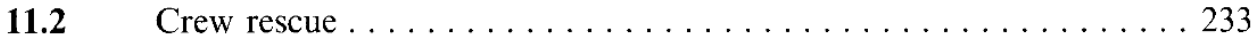

11.3. Range Safety Officer . . . . . . . . . . . . . . . . 239 


\section{Abbreviations}

$\begin{array}{ll}\text { ACES } & \text { Advanced Crew Escape Suit } \\ \text { ACT } & \text { Advanced Concepts Team } \\ \text { AGSM } & \text { Anti-G Straining Manoeuvre } \\ \text { AI } & \text { Artificial Intelligence } \\ \text { ALTEA } & \text { Anomalous Long Term Effects in Astronauts } \\ \text { AMP } & \text { Acoustics Measurement Program } \\ \text { APC } & \text { Armored Personnel Carrier } \\ \text { AQF } & \text { Astronaut Quarantine Facility } \\ \text { ARC } & \text { Ames Research Center } \\ \text { AR\&D } & \text { Automated Rendezvous and Docking } \\ \text { ATV } & \text { Automated Transfer Vehicle } \\ \text { BEES } & \text { Bioinspired Engineering of Exploration Systems } \\ \text { BLS } & \text { Basic Life Support } \\ \text { CapCom } & \text { Capsule Communicator } \\ \text { CBT } & \text { Computer Based Training } \\ \text { CEEG } & \text { Crew Escape Equipment Group } \\ \text { CEV } & \text { Crew Exploration Vehicle } \\ \text { CEVIS } & \text { Cycle Ergometer with Vibration Isolation System } \\ \text { CF } & \text { Canadian Forces } \\ \text { CHeCS } & \text { Crew Health Care Systems } \\ \text { CLL } & \text { Central Light Loss } \\ \text { CMO } & \text { Crew Medical Officer } \\ \text { CNM } & \text { Computer Network Modeling } \\ \text { CNS } & \text { Central Nervous System } \\ \text { COL } & \text { Crew Options List } \\ \text { CQRM } & \text { Crew Qualifications and Responsibility Matrix } \\ \text { CRM } & \text { Crew Resource Management } \\ \text { CSA } & \text { Canadian Space Agency } \\ \text { CSVS } & \text { Canadian Space Vision System } \\ \text { CT } & \text { Computer Tomography } \\ \text { CTN } & \text { Crew Training Notebook } \\ & \end{array}$




$\begin{array}{ll}\text { DAM } & \text { Debris Avoidance Manoeuvre } \\ \text { DARPA } & \text { Defense Advanced Research Project } \\ \text { DCP } & \text { Display and Control Panel } \\ \text { DCS } & \text { Decompression Sickness } \\ \text { DMS } & \text { Data Management System } \\ \text { DoF } & \text { Degrees of Freedom } \\ \text { D-RATS } & \text { Desert Research and Technology Study } \\ \text { EAC } & \text { European Astronaut Center } \\ \text { ECG } & \text { Electrocardiograph } \\ \text { ECLSS } & \text { Environmental Control Life Support System } \\ \text { EDL } & \text { Entry, Descent and Landing } \\ \text { EDR } & \text { European Drawer Rack } \\ \text { EDS } & \text { Earth Departure Stage } \\ \text { EEG } & \text { Electroencephalograph } \\ \text { EES } & \text { Emergency Escape System } \\ \text { EET } & \text { Emergency Egress Training } \\ \text { EMU } & \text { Extravehicular Mobility Unit } \\ \text { ENT } & \text { Ear, Nose, Throat } \\ \text { EPDS } & \text { Electrical Power Distribution System } \\ \text { EPM } & \text { European Physiology Module } \\ \text { ESA } & \text { European Space Agency } \\ \text { EST } & \text { Ejection Seat Training } \\ \text { ETC } & \text { European Transport Carrier } \\ \text { EVA } & \text { Extravehicular Activity } \\ \text { EVCPDS } & \text { Extravehicular Charged Particle Directional Spectrometer } \\ \text { FCB } & \text { Functional Cargo Block } \\ \text { FCER } & \text { Flight Crew Equipment Representative } \\ \text { FCL } & \text { Flight Crew Licensing } \\ \text { FCOD } & \text { Flight Crew Operations Directorate } \\ \text { FCR } & \text { Flight Control Room } \\ \text { FD } & \text { Flight Director } \\ \text { FEPA } & \text { Flight Equipment Processing Associate } \\ \text { FIT } & \text { Final Inspection Team } \\ \text { FOR } & \text { Frame of Resolution } \\ \text { FSL } & \text { Fluid Science Laboratory } \\ \text { FTS } & \text { Flight Termination System } \\ \text { GCR } & \text { Galactic Cosmic Radiation } \\ \text { GCTC } & \text { Gagarin Cosmonaut Training Center } \\ \text { G-LOC } & \text { Gravity-Induced Loss of Consciousness } \\ \text { GLS } & \text { Ground Launch Sequencer } \\ \text { GNC } & \text { Guidance Navigation and Control } \\ \text { GOR } & \text { Gradual Onset Rate } \\ \text { GRC } & \text { Glenn Research Center } \\ \text { HAI } & \text { High Altitude Indoctrination } \\ \text { HEAT } & \text { High-fidelity Environment Training } \\ & \end{array}$




\begin{tabular}{|c|c|}
\hline HMD & Head-Mounted Display \\
\hline HMP & Haughton Mars Project \\
\hline HOSC & Huntsville Operations Support Center \\
\hline HPS & Human Patient Simulator \\
\hline HRF & Human Research Facility \\
\hline IBMP & Institute for Biomedical Problems \\
\hline IGF & Insulin Growth Factor \\
\hline ILOB & Icarus Lunar Observatory Base \\
\hline IMS & Inventory Management System \\
\hline INS & Inertial Navigation System \\
\hline IOP & Intraocular Pressure \\
\hline IR & Infrared \\
\hline ISPR & International Standard Payload Rack \\
\hline ISRU & In Situ Resource Utilization \\
\hline ISS & International Space Station \\
\hline IST & Increment-Specific Training \\
\hline IVA & Intravehicular Activity \\
\hline IVCPDS & Intravehicular Charged Particle Directional Spectrometer \\
\hline JAA & Joint Aviation Authority \\
\hline JAR & Joint Aviation Requirements \\
\hline JGTF & Jake Garn Training Facility \\
\hline JSC & Johnson Space Center \\
\hline $\mathrm{KSC}$ & Kennedy Space Center \\
\hline LAS & Launch Abort System \\
\hline $\mathrm{LCC}$ & Launch Control Center \\
\hline LD & Launch Director \\
\hline LEE & Latching End Effector \\
\hline LEO & Low Earth Orbit \\
\hline LH2 & Liquid Hydrogen \\
\hline LLOX & Lunar Liquid Oxygen \\
\hline LMA & Laryngeal Mask Airway \\
\hline LMESSC & Lightweight Multi-Purpose Experiment Support Structure Carrier \\
\hline LOV & Loss of Vision \\
\hline LOX & Liquid Oxygen \\
\hline LPS & Launch Processing System \\
\hline $\mathrm{LRC}$ & Langley Research Center \\
\hline LSAH & Longitudinal Study of Astronaut's Health \\
\hline MAG & Maximum Absorbency Garment \\
\hline MBS & Mobile Base System \\
\hline MCAT & Medical College Admission Test \\
\hline $\mathrm{MCC}$ & Mission Control Center \\
\hline $\mathrm{MCP}$ & Mechanical Counter-Pressure \\
\hline MDD & Multispatial Disorientation Device \\
\hline MER & Mission Evaluation Room \\
\hline MIT & Massachusetts Institute of Technology \\
\hline
\end{tabular}




\begin{tabular}{|c|c|}
\hline MLC & Multimedia Learning Center \\
\hline MMPI & Minnesota Multiphasic Personality Inventory \\
\hline MMT & Mission Management Team \\
\hline MOI & Mars Orbit Insertion \\
\hline MOL & Manned Orbiting Laboratory \\
\hline MRI & Magnetic Resonance Imaging \\
\hline MRO & Mission Robotics Operator \\
\hline MSFC & Marshall Space Flight Center \\
\hline MSFT & Multi-Stage Fitness Test \\
\hline MSS & Mobile Servicing System \\
\hline MSSOTS & Mobile Servicing System Operations Training Simulator \\
\hline NBL & Neutral Buoyancy Laboratory \\
\hline NEEMO & NASA Extreme Environment Mission Operations Project \\
\hline NSBRI & National Space Biomedical Research Institute \\
\hline NTD & NASA Test Director \\
\hline OBS & Operational Bioinstrumentation System \\
\hline OETF & Operations Engineering Training Facility \\
\hline OFK & Official Flight Kit \\
\hline OID & Operational Intercommunications System \\
\hline PBAN & Polybutadiene Acrylonitrite \\
\hline PDGF & Power Data Grapple Fixture \\
\hline PLL & Peripheral Light Loss \\
\hline PLSS & Portable Life Support System \\
\hline PPC & Private Psychological Conference \\
\hline PPK & Personal Preference Kit \\
\hline RDS & Russian Docking System \\
\hline RHC & Rotational Hand Controller \\
\hline ROR & Rapid Onset Rate \\
\hline ROV & Remotely Operated Vehicle \\
\hline RRT & Rapid Response Team \\
\hline RSO & Range Safety Officer \\
\hline RSS & Rotating Service Structure \\
\hline RWS & Robotic Work Station \\
\hline SAR & Synthetic Aperture Radar \\
\hline SARJ & Solar Alpha Rotary Joint \\
\hline SCA & Simulation Control Area \\
\hline SCTF & Sonny Carter Training Facility \\
\hline SETI & Search for Extraterrestrial Intelligence \\
\hline SFU & Simon Fraser University \\
\hline SM & Service Module \\
\hline SOLO & Sodium Loading in Microgravity \\
\hline SOMD & Space Operations Mission Directorate \\
\hline SPE & Solar Particle Event \\
\hline SRB & Solid Rocket Booster \\
\hline $\mathrm{SRC}$ & Short-Radius Centrifuge \\
\hline
\end{tabular}




\begin{tabular}{ll} 
SSC & Stennis Space Center \\
SSMTF & Space Station Mockup and Training Facility \\
SSPF & Space Station Processing Facility \\
SST & Single System Trainer \\
SSTF & Space Station Training Facility \\
STFO & Spaceflight Training and Facility Operations \\
STL & Station Training Lead \\
SVMF & Space Vehicle Mock-up Facility \\
SVP & Structural Verification Plan \\
SWG & Structures Working Group \\
TBA & Trundle Bearing Assembly \\
TCDT & Terminal Countdown Demonstration Test \\
TCM & Trajectory Correction Manoeuvre \\
TCS & Thermal Control System \\
TEI & Trans-Earth Insertion \\
THC & Translational Hand Controller \\
TIC & Thermal Imaging Camera \\
TLI & Trans-Lunar Insertion \\
TORU & Tele-Operator Control System \\
TPS & Thermal Protection System \\
TVIS & Treadmill with Vibration and Isolation System \\
UPA & Urine Processing Assembly \\
USA & United Space Alliance \\
USAF & United States Air Force \\
VAB & Vehicle Assembly Building \\
VEG & Virtual Environment Generator \\
VR & Virtual Reality \\
VSE & Vision for Space Exploration \\
WRS & Water Recovery System \\
ZSF & Zvezda Space Facility \\
& \\
\hline &
\end{tabular}

